\title{
PARTICULARIDADES DAS PENITENCIÁRIAS FEMININAS
}

\author{
Felipe Tavares Ribeiro ${ }^{1}$ \\ Suelen Moreira ${ }^{2}$ \\ Rafael Gonzalez Bastos ${ }^{3}$ \\ Leonel Godinho da Silva Junior ${ }^{4}$ \\ Cristiano Ollé Pereira ${ }^{5}$ \\ Cesar Moraes de Souza ${ }^{6}$
}

RESUMO: A população carcerária feminina cresceu muito nos últimos anos, com isso o debate sobre as diferenças e particularidades dessas apenadas, em comparação com presos masculinos, ganhou espaço. É justamente sobre isso que o presente trabalho versa, através de uma revisão bibliográfica, diversos temas sobre essas particularidades serão apresentados. Assuntos como a gestação e a maternidade dentro das penitenciárias, saúde da mulher, as necessidades fisiológicas femininas, o material e a estrutura disponibilizados para as detentas. Com a finalidade de apontar as principais necessidades de melhora e as possíveis falhas, dentro do sistema carcerário, em garantia do direito da dignidade dessas mulheres.

Palavras-chave: Penitenciárias femininas. Apenadas. Sistema carcerário.

ABSTRACT: The female prison population has grown a lot in recent years, with this the debate on the differences and particularities of these inmates, compared to male prisoners, has gained space. It is precisely about this that the present work deals, through a bibliographic review, several topics about these particularities will be presented. Issues such as pregnancy and motherhood within prisons, women's health, female physiological needs, the material and structure made available to inmates. In order to point out the main needs for improvement and possible failures, within the prison system, in guaranteeing the right to dignity of these women.

Keywords: Female penitentiaries. Prison system.

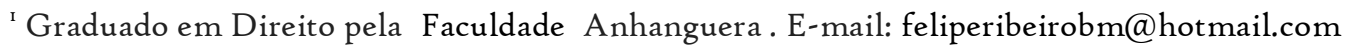

${ }^{2}$ Graduada em Educação Física. - Escola Superior de Educação Física pela Universidade Federal de Pelotas

${ }^{3}$ Engenheiro Civil Empresarial pela Universidade Federal do Rio Grande do Sul

${ }^{4}$ Tecnologia em sistemas para internet. Instituto Federal do Rio Grande do Sul

${ }^{5}$ Graduado em Educação Física pela Universidade Federal de Rio Grande do Sul -FURG

${ }^{6}$ Graduado de Engenharia Mecânica Universidade Federal de Rio Grande - FURG
} 


\section{INTRODUÇÃO}

No Brasil cresce o número de mulheres presas anualmente, com isso cresce a discussão sobre as diferenças necessárias entre os tipos de penitenciárias masculinas e femininas. Em muitos presídios ainda existem estruturas mistas, que são locais onde não existe separação por gêneros, a separação é feita apenas por alas ou celas. Esse último está longe de ser a situação ideal de estrutura para detentas. Além do risco de assédio que elas sofrem, existem particularidades necessárias às mulheres, e nesses ambientes a estrutura é feita para homens e, sem adaptação nenhuma, utilizada por mulheres.

O objetivo desse trabalho é, através da revisão bibliográfica, identificar as particularidades do sistema prisional feminino. Dentro desse contexto identificar e discutir sobre direitos das presidiárias e a realidade das penitenciárias brasileiras.

A importância da discussão de assuntos como este dá-se ao fato de muitas vezes as detentas não terem conhecimentos de seus direitos. Ou não terem suas individualidades respeitadas em momentos delicados como gestação e até mesmo questões fisiológicas como ciclo menstrual.

Existem muitos artigos e livros sobre mulheres na condição de detentas. A maior parte fala sobre os motivos das mesmas se encontrarem nessa situação, dos crimes cometidos e sobre a culpa direta ou indireta por estarem presas. Mas poucos relatam sobre a realidade da estrutura física em que elas se encontram e da falta do básico, que não é percebido como tal.

Espera-se que com este trabalho seja possível fazer um levantamento de informações relevantes para indicar as principais diferenças entre os sistemas masculino e feminino. Apontando, também, as principais faltas e falhas que essa falta de diferenciação acarreta.

\section{AS MULHERES E O SISTEMA CARCERÁRIO}

O sistema carcerário Brasileiro possui diversos problemas e está na terceira posição de maior população carcerária do mundo. Quanto ao número de mulheres presas, ocupa a quarta posição (CARVALHO e CARDOSO, 2019).

A maior parte dos estabelecimentos prisionais é voltada para homens, 75\%, e a menor parte é destinada para mulheres, menos de 7\%. Existem, inclusive, mais penitenciárias mistas 
(I8\%) do que somente femininas (INFOPEN, 2017). Como a maior parte da população carcerária é masculina, esses estabelecimentos mistos são penitenciárias voltadas ao sistema masculino, onde são disponibilizadas celas ou alas para apenadas. Tendo a maioria dos detentos do sexo masculino, as detentas não têm suas peculiaridades de gênero consideradas.

Inclusive nos estabelecimentos exclusivamente femininos, essas peculiaridades não são observadas. Como ressalta Santoro e Pereira (2018):

Ao se olhar para as mulheres que cumprem pena privativa de liberdade, o cárcere feminino exprime e revela de forma clara as desigualdades de gênero presentes nos diferentes espaços sociais, mas que ganham maior proporção no ambiente prisional devido a falta de melhores condições de assistência às presas que ali estão confinadas.

Embora aprisionadas em espaços especificamente voltados para o cárcere feminino, as detentas ainda estão submetidas a ideia de que o criminoso é quase que exclusivamente do sexo masculino e, portanto, a formulação dos espaços prisionais deve ser proporcional a esta demanda, isto é, praticamente voltada para os homens. (SANTORO e PEREIRA, 2018, p.89).

\section{I.I Realidade dos presídios femininos}

A cadeia é um local para que o indivíduo cumpra sua pena, privado apenas do direito à liberdade, portanto deveria ter o restante de seus direitos preservados. Mas muitas vezes as mulheres não têm seus direitos humanos respeitados, sem garantia do básico. Por tratarem as mulheres como tratam os homens, o sistema carcerário não leva em consideração muitos aspectos, inclusive de higiene e dignidade dessas detentas.

No livro Presos que menstruam, Queiroz (2015) expõe muitos desses aspectos, que são esquecidos pelo Estado. Tais como a necessidade das apenadas de precisarem de papel higiênico em maior quantidade, já que o utilizam em todas idas ao banheiro, de absorventes, de exames ginecológicos de rotina (ex: Papanicolau), de exames de acompanhamento prénatal, quando grávidas. A fim de elucidar que realmente o básico é negado, em forma de esquecimento, a essas mulheres, Queiroz (2015) relata que muitas dessas mulheres, por exemplo, juntam miolo de pão para dele se utilizar quando estiverem menstruadas.

Klanovicz e Bugai (2019, p. 93), corroboram, afirmando que “[...] as mulheres encarceradas possuem condições específicas de vulnerabilidade e demandam atenção especial 
do Estado que viola de modo acentuado inúmeros direitos das mulheres encarceradas.”. E ainda acrescentam:

De modo geral, as mulheres presas, no Brasil, não estão privadas apenas da liberdade, mas também de seu direito à intimidade, à maternidade, à privacidade, à saúde, dentre outras garantias fundamentais.

Não se trata, no entanto, de uma questão atrelada unicamente à privação de liberdade da pessoa, mas sim à privação da liberdade da mulher, ou seja, a privação de gênero, pois o instituto da prisão no Brasil, tal qual em todas as demais áreas sociais, ainda é dominado pela conceituação de gênero. (KLANOVICZ e BUGAI, 2019, p. 92).

Essa violação de direitos das mulheres fica mais visível ainda nas penitenciárias mistas. Esses ambientes masculinos, apenas adaptados para apenadas, são incapazes de servirem para o que se propõe, como já foi descrito anteriormente, pois não foram construídos levando em consideração as peculiaridades da mulher. Carvalho e Cardoso (2019), afirmam, acrescentando, ainda, a situação especifica que a maternidade traz:

[...] estabelecimentos em que a estrutura prisional e os serviços penais foram formulados para o público masculino e posteriormente adaptados para custódia de mulheres e são, assim, incapazes de observar as especificidades de espaços e serviços destinados às mulheres, que envolvem o aleitamento na prisão, espaços para os filhos, além de locais adequados para a custódia de mulheres gestantes, entre outras especificidades. (CARVALHO e CARDOSO, 2019, p.io).

Risso e Moreira (2019) corroboram, afirmando que:

As especificidades do gênero feminino, como a maternidade, o impacto físico e psíquico da alteração cíclica dos hormônios, a gravidez, a amamentação, a saúde ginecológica e a higiene não encontram adequação em um sistema concebido para receber homens. Além das questões diretamente associadas à apenada, cabe ressaltar que as mulheres encarceradas, em geral, permanecem como as responsáveis pelo sustento de seus filhos menores, muitos afastados do convívio com a mãe e passados à guarda de familiares, institucionalizados em creches ou postos à adoção. (RISSO e MOREIRA, 2019).

Outro fator agravante é o abandono que essas mulheres sofrem, não só do Estado, mas também de seus familiares. Muitas vezes não são aplicadas estratégias de reinserção dessas mulheres na sociedade e consequentemente nas suas famílias. Conforme declaram Carvalho e Cardoso (2019):

As mulheres se distanciam-se de sua família, são forçadas a se separarem de seus filhos e são completamente abandonadas por seus então companheiros. Nesse contexto, o cárcere é um fator agravante para a situação dessas mulheres, pois, sem perspectivas, entram, permanecem e saem de dentro de um sistema penal que não se propõe a realizar uma verdadeira política de ressocialização de seus custodiados e posterior reinserção na sociedade. (CARVALHO e CARDOSO, 2019, p.2). 


\subsection{Leis que amparam as presidiárias}

A Constituição da República Federativa do Brasil de 1988 afirma que as mulheres deveriam receber um tratamento carcerário diferenciado, como pode ser verificado no Art. 5:

XLVIII - a pena será cumprida em estabelecimentos distintos, de acordo com a natureza do delito, a idade e o sexo do apenado;

$[\ldots]$

$\mathrm{L}$ - às presidiárias serão asseguradas condições para que possam permanecer com seus filhos durante o período de amamentação.

A Lei de Execução Penal, no seu Art. I4, descreve que "A assistência à saúde do preso e do internado de caráter preventivo e curativo, compreenderá atendimento médico, farmacêutico e odontológico" e mais especificamente no parágrafo $3^{\circ}$, afirma que “será assegurado acompanhamento médico à mulher, principalmente no pré-natal e no pós-parto, extensivo ao recém-nascido.”.

Na Lei Complementar 153, de 9 de dezembro de 2015, no Art. 3 consta que "é dever da instituição penal a implantação e manutenção de berçário, creche e seção destinada à gestante e parturiente".

A Lei no $12.962 / 2014$, visa garantir a convivência da criança e do adolescente com pais privados de liberdade, conforme descrito no parágrafo 2 o do Art. 23 "a condenação criminal do pai ou da mãe não implicará a destituição do poder familiar, exceto na hipótese de condenação por crime doloso, sujeito à pena de reclusão, contra o próprio filho ou filha”.

Existem essas e outras leis que visam garantir os direitos básicos às detentas. Mas conforme Risso e Moreira (2019), há necessidade de se garantir que realmente todas internas tenham acesso a seus direitos.

É visível que existem leis que reconhecem a situação de vulnerabilidade das mulheres encarceradas e de seus filhos, porém, a própria inovação legislativa que tem por finalidade a manutenção do vínculo familiar prescinde de reformulação quanto ao seu alcance para que não se permita negar o benefício quanto ao merecimento de se reunir ao seu filho. (RISSO e MOREIRA, 2019).

\section{I.3 Gravidez, maternidade e detenção}

Embora existam leis que garantiriam direitos as gestantes em situação de cárcere, conforme apresentado no item 2.2 deste trabalho, muitas vezes na realidade essas leis não são cumpridas. Andrade, Souza e Teotônio (2019), expõem exatamente isso no seguinte trecho: 
É de suma importância que mesmo dentro do cárcere, a mulher, tenha os seus direitos mantidos, pois a Constituição é norma das normas, portanto nenhuma outra lei pode se opor, e ninguém pode "desobedecer" a nenhum de seus princípios, as garantias e os direitos fundamentais.

O que a realidade nos mostra é algo bem diferente, onde muitas vezes tanto as mulheres quanto os homens vivem em presídios superlotados, pois a população brasileira continua crescendo, bem como a do cárcere, e a constituição e seus direitos muitas vezes estão sendo totalmente violados. (ANDRADE, SOUZA e TEOTÔNIO, 2019).

Além das mães que estão na condição de presas, com seus direitos negados, as crianças também acabam sendo prejudicadas. Diuana, Corrêa e Ventura (2017) narram que muitas mães acreditam que enquanto estiverem amamentando terão o contato com o filho, então deixam de inserir outros alimentos com medo que os mesmos substituam o leite materno. E muitas outras, sem saber do tempo que tem com o bebê, acreditam que o melhor é prepará-los para a situação que os espera, longe delas. E acabam interrompendo a amamentação precocemente, acreditando que assim as crianças sofrerão menos com a separação.

Ainda na questão alimentação, Diuana, Corrêa e Ventura (2017) relatam que as cadeias não permitem que as mães preparem o que julgam necessário para seus filhos e também tem o horário de alimentação estipulado pelas direções, tirando o poder delas de decidir o que é melhor para os seus filhos. Diuana, Corrêa e Ventura (2017, p.736) completam “[...] as rotinas e horários constituem constrangimentos à liberdade das crianças e à autonomia das mães, já que as crianças e as mães precisam se ajustar a estes horários, que não contemplam diferenças de idade das crianças e de suas necessidades.”.

Quanto ao tempo em que a criança deve passar junto com a mãe, dentro do presidio, existem diversos debates sobre isso, conforme destacam Andrade, Souza e Teotônio (2019):

Muitos pesquisadores estudam os prós e contras de se viver dentro de um presidio, por isso, enquanto os bebês estão dentro do ventre, a expectativa de seu nascimento é ainda maior, pois surgem diversos questionamentos, dentre eles, por quanto tempo a criança viverá em um presidio? Como será sua convivência com a população carcerária?

Mas o que nunca se passa pela cabeça da população é que uma criança também necessita de cuidados maternos em seus primeiros dias de vida, necessitando-se manter uma conexão parental com sua genitora. (ANDRADE, SOUZA e TEOTÔNIO, 2019).

Essa ligação entre mãe e filho é muito importante, mas sem estrutura adequada acaba se transformando em transtorno e frustação para essas mulheres. Segundo dados do 
INFOPEN Mulheres (2017), do total de unidades femininas, menos da metade dispõe de cela ou dormitório adequado para gestantes. Em relação à existência de berçários ou centro de referência materno infantil, 32\% das unidades femininas têm esse espaço. As unidades mistas, por sua vez, contam com apenas 3\% de espaços separados para o fim referido.

Conforme Diuana, Corrêa e Ventura (2017), existe a situação da separação precoce, com receio do filho estar em um ambiente prisional, sem estrutura adequada, a mãe se separa antes do tempo mínimo, para o filho não se privar de liberdade como ela. Isso quando essas mulheres possuem famílias para ficarem de responsáveis pela guarda. $\mathrm{Na}$ maioria das vezes a separação é motivo de muita preocupação. Diuana, Corrêa e Ventura (2017, p.735) completam, descrevendo a angustia de muitas mães prisioneiras, em terem os cuidados de seus filhos encaminhados à outras pessoas, "Temem que sejam maltratados, que elas não consigam mais vê-los e que não possam recuperar sua guarda quando saírem da prisão.”.

Dentre tantas preocupações das detentas gestantes e mães, uma das principais, segundo Diuana, Corrêa e Ventura (2017), é quanto à saúde de seus filhos, conforme relatam:

Entre a demanda dirigida às mulheres para que se responsabilizem por seus filhos e a condição de privação de liberdade, na qual têm sua capacidade de agir e decidir constrangidas pela vigilância e pelo controle disciplinar, a atenção à saúde das crianças constitui uma das maiores fontes de tensão e insatisfação das mães e de conflitos com a administração penitenciária. Nesses casos, as mulheres presas sentem-se pressionadas entre ameaças veladas ou claras de serem punidas ou de verem os problemas de saúde dos filhos se agravarem por demora ou desassistência à saúde. (DIUANA, CORRÊA e VENTURA, 2017, p.737).

E ainda destacam a normalização da falta de tratamento digno a mulheres nessa situação:

[...] as mulheres estão expostas a muitas violências decorrentes de seu encarceramento, que fazem com que o sofrimento e o sacrifício pelo "bem dos filhos" sejam aceitos como parte integrante do exercício da maternidade, em especial pelas mulheres que desejam permanecer com seus filhos junto a elas na prisão ou que encontram dificuldades para encaminhá-los a pessoa de sua confiança. (DIUANA, CORRÊA e VENTURA, 2017, p.743)

Com isso é evidente a necessidade de se discutir a possibilidade de uma maior autonomia para essas mães, além de leis que amparem, fornecendo recursos e assegurando direitos, a essas mulheres e crianças nessas condições. Além de estruturas adequadas para permanência das crianças e mãe juntas. 


\section{CONSIDERAÇÕES FINAIS}

Com este trabalho conclui-se que, embora existam leis que protejam os direitos das detentas, existe muito o que se debater e acrescentar nas discussões de peculiaridades necessárias de serem observadas nas penitenciarias que atendem ao público feminino.

É necessário fazer um estudo mais especifico sobre a realidade nas penitenciárias femininas e mistas. Não somente um estudo estatístico com número de detentas e delitos cometidos pelas mesmas, terá de se estudar também a sua estrutura como um todo incluindo as necessidades dessas mulheres.

Buscando maneiras de desvincular-se de espaços mistos, que muitas vezes apresentam riscos físicos (de abuso sexual e violência). Será preciso, também, compreender que esses espaços físicos precisam fornecer estrutura preparada para maternidade, com salas especificas. Além de estudar formas de construir práticas de maternidade mais humanas. E atender as especificidades de saúde das mulheres.

Embora as mulheres façam parte da população carcerária em uma porcentagem muito menor que a masculina, isso não pode ser justificativa para as mesmas não terem seus direitos e peculiaridades observados e respeitados. É necessário que o sistema olhe para essas mulheres, respeitando suas diferenças, e forneça o mínimo de dignidade para as mesmas.

\section{REFERÊNCIAS}

ANDRADE, M. B. SOUZA, G.V. TEOTÔNIO, P.J.F. A realidade do encarceramento feminino e a invisibilidade de mulheres grávidas no sistema prisional. Disponível em: $<$ https://jus.com.br/artigos/74383/a-realidade-do-encarceramento-feminino-e-ainvisibilidadede-mulheres-gravidas-no-sistema-prisional>, Acesso em 31/oI/2022.

BRASIL. Constituição (1988). Constituição da República Federativa do Brasil, 1988. Brasília: Senado Federal, Centro Gráfico, 1988.

BRASIL. Lei Complementar nำ 153, Brasília, DF, o9 dez 2015.

BRASIL. Lei no 12.962, Brasília, DF, o8 abr. 2014.

BRASIL. Lei de Execução Penal. Lei no 7.210, Brasília, DF, II jul. I984. 
CARVALHO, M. I. C. A. de. CARDOSO, G. M. O feminino em cárcere: reflexões acerca do tratamento dado às mulheres pelo sistema prisional brasileiro. Revista Científica Eletrônica do Curso de Direito, $15^{\underline{a}}$ ed., jan. 2019.

DEPEN. Levantamento Nacional de Informações Penitenciárias INFOPEN. Disponível em: $<$ http://depen.gov.br/DEPEN/depen/sisdepen/infopen/relatorios-sinteticos/infopen-jun2017-rev-I2072019-0721.pdf $>$, Acesso em 17/05/2020.

DEPEN. Relatório temático sobre mulheres privadas de liberdade INFOPEN mulheres. Disponível em: <http://depen.gov.br/DEPEN/depen/sisdepen/infopenmulheres/copy_of_Infopenmulheresjunho2017.pdf>, Acesso em 17/05/2020.

DIUANA, V. CORREAA, M. C.D.V. VENTURA, M. Mulheres nas prisões brasileiras: tensões entre a ordem disciplinar punitiva e as prescrições da maternidade. Physis Revista de Saúde Coletiva, Rio de Janeiro, n.27, p. 727-747, 2017.

KLANOVICZ, L.R.F. BUGAI, F.A. MULHERES NO CÁRCERE: A estrutura do sistema prisional e a construção do gênero no Brasil. História \& Perspectivas, Uberlândia, n.59, p. 8o97, jul.-dez. 2019.

QUEIROZ, N. Presos que menstruam: a brutal vida das mulheres - tratadas como homensnas prisões brasileiras. I. ed. São Paulo: Record, 2015.

RISSO, M.F. MOREIRA, C.V.R. S. Encarceramento Feminino: Desafios Invisíveis. Disponível em: <https://ambitojuridico.com.br/cadernos/direito-processualpenal/encarceramento-feminino-desafios-invisiveis/>, Acesso em 31/ol/2022.

SANTORO, A.E.R. PEREIRA, A.C.A. Gênero e prisão: o encarceramento de mulheres no sistema penitenciário brasileiro pelo crime de tráfico de drogas. Meritum, Belo Horizonte, v.I3, n.I, p. 87-II2, jan.-jun. 2018. 